\title{
Percepções Sobre Metodologias Ativas de Aprendizagem de Programação no Ensino Profissionalizante
}

\author{
Mayara Dias Gonçalves ${ }^{1}$, Suenny Mascarenhas Souza ${ }^{1}$, \\ Felipe Leonardo Furtado Barros ${ }^{1}$, Roberto Almeida Bittencourt ${ }^{1}$ \\ ${ }^{1}$ UEFS - Universidade Estadual de Feira de Santana \\ Av. Transnordestina, s/n, Novo Horizonte \\ Feira de Santana - BA, Brasil - 44036-900 \\ \{mayaradiasg, suenny.s,felipelfbarros\}@gmail.com, roberto@uefs.br
}

\begin{abstract}
Vocational education has specific issues that differ from higher education, focusing more on practice rather than on theory, as well as aiming to educate professionals to solve demands of the local industry. In that context, where preparing students to the real world becomes more important, this paper investigates students' experiences with active learning methodologies, especially PBL. Results show positive trends, especially on students' motivation and autonomy.
\end{abstract}

Resumo. O ensino profissionalizante possui particularidades que o fazem diferir do ensino superior, tendo destaque o foco mais prático e menos acadêmico de seus cursos e a formação de profissionais orientada às demandas da indústria local. Nesse contexto, onde é cada vez mais importante preparar o estudante para o mundo real, este trabalho investiga a experiência dos estudantes com metodologias ativas de aprendizagem, especialmente PBL. Os resultados apontam tendências positivas, especialmente na motivação e autonomia dos estudantes.

\section{Introdução}

Ensinar programação orientada a objetos (POO) como segundo paradigma é uma tarefa difícil por alguns motivos: a complexidade intrínseca destas linguagens, a complexidade dos ambientes de desenvolvimento profissionais normalmente utilizados com estas linguagens e a própria mudança de um paradigma imperativo para o orientado a objetos. Some-se a isto o fato de linguagem, ambiente e paradigma terem de ser aprendidos em um período tipicamente curto de uma disciplina, seja na graduação ou na educação profissional [Bittencourt et al. 2013a]. Nesta última, o problema se agrava ainda mais pelas dificuldades de um público tipicamente jovem que, muitas vezes, termina por abandonar estes cursos [Machado et al. 2006, Cravo 2012].

Diversos trabalhos descrevem estratégias que objetivam potencializar a aprendizagem e a retenção do conhecimento de POO. Alguns descrevem características de linguagens orientadas a objeto adequadas [Kölling 1999a]. Outros apontam a necessidade de ambientes de desenvolvimento adaptados a novatos [Kölling 1999b]. Há também trabalhos que procuram focalizar a atenção na abordagem utilizada, já considerandos os avanços em linguagens e ambientes adaptados a novatos [Vahldick 2007, Santos et al. 2015]. Por exemplo, Vahldick (2007) utilizou ambientes de desenvolvimento 
VI Congresso Brasileiro de Informática na Educação (CBIE 2017)

Anais dos Workshops do VI Congresso Brasileiro de Informática na Educação (WCBIE 2017)

lúdicos em sala de aula, como o Greenfoot, e exemplos ilustrativos para apresentar os conceitos de POO . Santos et al. (2015) descreveram a utilização de Greenfoot, Robocode e BlueJ em oficinas oferecidas a estudantes do segundo semestre de um curso de Engenharia de Computação, realizadas antes do início das aulas regulares. E também há trabalhos que descrevem o uso de metodologias ativas, como a aprendizagem baseada em problemas (do inglês, PBL) no ensino de programação [Santos et al. 2008b, Bittencourt et al. 2013b]. Apesar da diversidade de pesquisas, a maioria delas é focada no ensino de programação para estudantes da educação superior, um contexto diferente do da educação profissionalizante.

Metodologias tradicionais de ensino com aulas expositivas, apesar de capazes de fornecer uma boa base teórica, nem sempre expõem os alunos a aplicações práticas significativas dos conceitos que aprenderam, nem trabalham habilidades técnicas ou processuais específicas, tornando o conhecimento passível de esquecimento ou dificultando a sua aplicação em contextos reais. PBL é uma estratégia educacional centrada no estudante, que o ajuda a desenvolver habilidades processuais como o raciocínio e a comunicação, além de colocar o estudante no centro do processo de construção do conhecimento [Santos et al. 2007]. Apesar de largamente difundida em universidades, tanto no contexto mais tradicional da área de saúde [Albanese and Mitchell 1993] como também na área de computação [Oliveira et al. 2013], não encontramos trabalhos prévios que utilizem PBL na educação profissionalizante de nível médio.

Este trabalho descreve e analisa, através de um estudo de caso, uma experiência de ensino-aprendizagem baseada em PBL em uma disciplina de programação no ensino profissionalizante de nível médio, mais particularmente, em um curso técnico de Informática. Os resultados preliminares são positivos em relação à autonomia desenvolvida pelos estudantes, à motivação para o estudo e realização dos trabalhos, embora também sejam percebidos alguns pontos fracos de PBL, especialmente com alguns estudantes que se sentiram, por vezes, excluídos das atividades.

\section{Fundamentação Teórica}

Em seu artigo sobre avaliação de aprendizagem ativa, Prince (2004) descreve aprendizagem baseada em problemas (PBL) como um método instrucional onde problemas são introduzidos no início do ciclo instrucional e usados para contextualizar e motivar a aprendizagem que se seguirá, envolvendo de maneira significativa a aprendizagem autodirigida pelos estudantes.

PBL teve origem no ensino de Medicina [Barrows and Tamblyn 1980], com as primeiras experiências ocorrendo na Universidade de McMaster, no Canadá. Em seguida, foi adotada pela Universidade de Harvard e, a partir daí, se espalhou pelo mundo. A metodologia consiste no estímulo à resolução de problemas através de pesquisa colaborativa em pequenos grupos de estudantes. Além do aprendizado de conceitos teóricos, a metodologia apoia o desenvolvimento de habilidades de trabalho em equipe, raciocínio lógico e crítico e a capacidade de pesquisar. Como a aprendizagem passa a ser centrada no estudante, em sua tentativa de solucionar os problemas, o professor passa a ter o papel de um tutor, atuando como um facilitador do processo, questionando e orientando os estudantes quando necessário [Uden and Beaumont 2005].

Metodologias ativas de ensino-aprendizagem baseadas em PBL tem sido 
VI Congresso Brasileiro de Informática na Educação (CBIE 2017)

Anais dos Workshops do VI Congresso Brasileiro de Informática na Educação (WCBIE 2017)

usadas em algumas universidades do Brasil. Na área de Medicina, por exemplo, a Faculdade de Marília e a Universidade Estadual de Londrina foram pioneiras na implantação de PBL como método de ensino [Berbel 1998]. A Universidade Estadual de Feira de Santana (UEFS) adotou este método na criação de seu curso de Engenharia de Computação em 2003 [Bittencourt and Figueiredo 2003, Santos et al. 2007]. A utilização de PBL no ensino de programação no curso de Engenharia de Computação da UEFS já foi relatada previamente em detalhe na literatura. [Santos et al. 2008b, Santos et al. 2008a, Santos and Ângelo 2009, Angelo et al. 2010, Bittencourt et al. 2013b, Angelo et al. 2014]. Destacamos, a seguir, algumas destas experiências.

As primeiras experiências relatando o uso de PBL para ensinar POO na UEFS analisam os resultados do ponto de vista dos estudantes e dos professores [Santos et al. 2008b, Angelo et al. 2010, Angelo et al. 2014]. Através de questionários, os estudantes relatam as sessões tutoriais como mais produtivas que tanto as aulas expositivas como o estudo extraclasse. Além disso, quanto mais motivados com os problemas, menos importantes eram as aulas expositivas. Quanto aos professores, a partir do relato de suas discussões semanais de acompanhamento, perceberam-se benefícios e dificuldades. Para eles, os principais benefícios foram o desenvolvimento de habilidades como trabalho em equipe, comunicação oral, pensamento crítico, autonomia e "aprender a aprender". Por outro lado, as maiores dificuldades foram elaborar problemas combinando situações reais, motivação, conhecimentos da disciplina e tempo adequado para resolução.

Santos e Angelo (2009) utilizam a Taxonomia de Bloom Revisada para analisar os problemas em termos de objetivos a serem alcançados no contexto anterior. Através da taxonomia, são descritos aspectos a serem relembrados, entendidos, aplicados, analisados, avaliados e criados. Com isso, os tutores responsáveis pela elaboração dos problemas são capazes de integrar a relação dos objetivos de cada problema com o escopo da disciplina em que ele é aplicado. Isto facilita a compreensão das peculiaridades do problema para outros tutores não envolvidos em sua elaboração, a definição do tempo de desenvolvimento do produto e o feedback a ser dado aos estudantes.

Bittencourt et al. (2013) descrevem as experiências obtidas em um estudo integrado de Programação baseado em PBL após a inserção da disciplina de Projeto de Sistemas. Buscou-se reduzir a complexidade de mudança de paradigma ao introduzir aos estudantes aspectos de design que facilitam a programação orientada a objetos. O trabalho relata duas experiências em semestres consecutivos, buscando identificar os pontos positivos da mudança recém-aplicada e os aspectos a serem melhor trabalhados. As lições aprendidas foram: evitar problemas longos que levem a questões de manutenção de código, uma vez que os aprendizes podem acumular deficiências, e a dosagem excessiva dos conceitos abordados em um problema, fatores que podem reduzir a motivação dos estudantes; a importância da metodologia PBL para desenvolver competências de comunicação, autodidatismo e trabalho em equipe nos estudantes; e a integração do conhecimento das disciplinas do estudo integrado, o que permite ao estudante ter a experiência de trabalhar em várias etapas do ciclo de vida de um software. 
VI Congresso Brasileiro de Informática na Educação (CBIE 2017)

Anais dos Workshops do VI Congresso Brasileiro de Informática na Educação (WCBIE 2017)

\section{Metodologia}

A estratégia de pesquisa utilizada foi o estudo de caso, uma metodologia de pesquisa que busca compreender um problema ou fenômeno através de um caso específico, utilizado como ilustração [Creswell 2010]. A seguir, descrevemos cenário, participantes, abordagem e a coleta e análise de dados.

\subsection{Cenário}

O SENAI Bahia oferece o curso Técnico em Informática em Feira de Santana. Este curso possuía duas turmas ativas quando da realização deste trabalho. O curso tem a duração de quatro semestres e é composto de quatro módulos de disciplinas relacionadas ao desenvolvimento de software.

A disciplina Desenvolvimento de Sistemas I faz parte do terceiro módulo do curso, juntamente com Modelagem de Sistemas e Projeto de Final de Curso I. As duas primeiras disciplinas são ofertadas em sequência, e concorrentemente com Projeto de Final de Curso I. Este módulo envolveu três docentes, sendo dividido entre aulas teóricas e práticas. $\mathrm{O}$ Projeto de Final de Curso segue a metodologia alemã Theoprax, que objetiva o desenvolvimento de produtos para empresas reais. Este trabalho foi construído utilizando as experiências obtidas na disciplina Desenvolvimento de Sistemas I, cuja professora é também autora do presente artigo.

\subsection{Participantes}

Os participantes da pesquisa foram nove estudantes do terceiro módulo do curso técnico em Informática. Todos os participantes são do sexo masculino com idades variando entre 17 e 25 anos (desvio padrão de 2,7). Dos 11 estudantes, nove concordaram em participar da pesquisa. Todos já tinham contato prévio com programação em outras disciplinas do curso e possuíam conhecimento introdutório de programação orientada a objetos.

\subsection{Abordagem}

O objetivo da disciplina Desenvolvimento de Sistemas I é capacitar o estudante com conceitos de orientação a objetos $(\mathrm{OO})$ e programação Web. A Tabela 1 sintetiza o conteúdo da disciplina referente aos conceitos de POO, tema do problema utilizado.

Tabela 1. Conteúdo Programático de POO na disciplina

\begin{tabular}{|l|l|}
\hline \multicolumn{2}{|c|}{ Conteúdos } \\
\hline 1. Introdução à Orientação a Objetos & 9. Métodos de Classes \\
\hline 2. Modelos Orientados a Objetos & 10. Construtores \\
\hline 3. Classes & 11. Polimorfismo \\
\hline 4. Objetos & 12. Herança \\
\hline 5. Atributos & 13. Modificador Protected \\
\hline 6. Tipos de Atributos & 14. Sobrecarga de Métodos \\
\hline 7. Modificadores de Acesso & 15. Classes Abstratas \\
\hline 8. Getters e Setters & 16. Interfaces \\
\hline & 17. Classes Estáticas \\
\hline
\end{tabular}

Após ter ministrado 12 aulas expositivas sobre os assuntos na Tabela 1, a professora apresentou uma visão geral da abordagem PBL e o problema aos estudantes. O 
VI Congresso Brasileiro de Informática na Educação (CBIE 2017)

Anais dos Workshops do VI Congresso Brasileiro de Informática na Educação (WCBIE 2017)

problema consistia em desenvolver um pequeno sistema para gerenciar informações referentes a professores, alunos e disciplinas de uma escola da região. Foi contada uma história fictícia para contextualizar a atividade como um problema do mundo real. Os estudantes deveriam implementar uma solução para o armazenamento das informações citadas. O software deveria ser capaz de cadastrar, editar e listar informações referentes a alunos, professores e disciplinas, além de listar as disciplinas alocadas a um aluno ou professor. O estudante deveria também implementar uma solução que armazenasse em disco as informações cadastradas para que elas fossem resgatadas sempre que o sistema fosse iniciado. O problema abrangeu o conteúdo visto em sala de aula e apresentava um desafio extra (armazenamento) para motivar a autonomia dos estudantes.

\subsection{Coleta e Análise de Dados}

Ao final da disciplina, um questionário foi respondido pelos nove participantes da pesquisa. Os dados dos participantes foram anonimizados. O questionário incluiu perguntas relacionadas a motivação, sensação de autonomia, trabalho em grupo, dentre outros conceitos. O questionário também buscou abordar as diferenças de percepção dos estudantes entre o método tradicional de ensino e metodologias ativas, com ênfase em PBL. Além dos dados quantitativos, a professora registrou também suas impressões sobre esta vivência com a turma. A análise dos dados foi realizada através de estatísticas descritivas.

\section{Resultados}

Os resultados obtidos a partir dos questionários foram divididos em categorias, abordando inicialmente aprendizagem ativa de forma geral, seguido por questões específicas sobre PBL e encerrando com questões sobre as aulas tradicionais vivenciadas previamente.

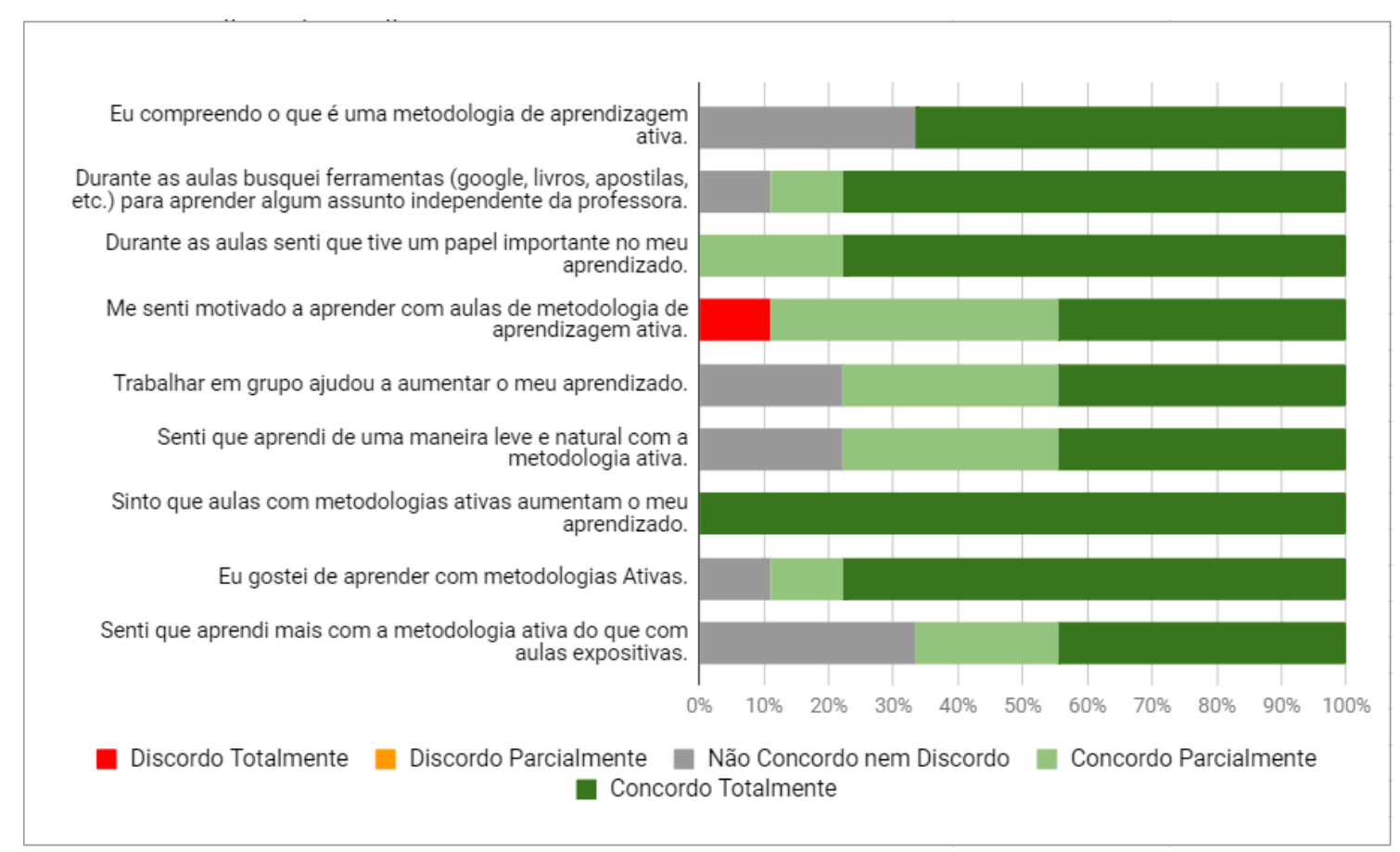

Figura 1. Percepções sobre metodologias de aprendizagem ativa

Percepções sobre metodologias ativas. Como mostrado na Figura 1, em relação à percepção dos alunos sobre o uso de uma metodologia ativa, os resultados foram posi- 
VI Congresso Brasileiro de Informática na Educação (CBIE 2017)

Anais dos Workshops do VI Congresso Brasileiro de Informática na Educação (WCBIE 2017)

tivos para todos os questionamentos. Os alunos concordaram parcial ou totalmente que a metodologia PBL teve um papel importante na formação do seu conhecimento. 88,9\% se sentiram motivados e buscar materiais de estudo e pesquisa além do que lhes era apresentado pela professora. Um fator importante foi a percepção da aprendizagem através do trabalho em grupo, reconhecido pela maioria dos participantes.

Percepções sobre PBL. A Figura 2 apresenta as respostas às perguntas sobre PBL. Os resultados apontam que os estudantes, em sua maioria $(66,7 \%)$, concordaram parcialmente que aprenderam tudo o que tinham de aprender, com apenas 22,2\% concordando plenamente. Além disso, observamos que parte dos estudantes sentiu certa desorientação, com 44,4\% concordando parcial ou totalmente com a afirmação de sentir-se perdido em alguns momentos. Por outro lado, $88.9 \%$ dos alunos discordaram total ou parcialmente de que se sentiram excluídos durante as atividades. Não houve nenhuma concordância com a afirmação de ter dificuldades de aprender com PBL, estando as respostas concentradas na discordância total ou parcial $(66,7 \%)$.

$88,8 \%$ dos participantes afirmaram ter concordado parcial ou totalmente que PBL os ensinou a buscar e selecionar melhor o conhecimento de que necessitam. Outra habilidade que PBL fez aprimorar nos estudantes foi o trabalho em grupo (77,8\% de concordância). 88,9\% dos participantes concordaram totalmente que compartilhar ideias com os colegas ampliou sua visão e os ajudou a resolver problemas. Os estudantes também afirmaram que PBL trouxe uma experiência significativa para suas vidas $(88,9 \%)$.

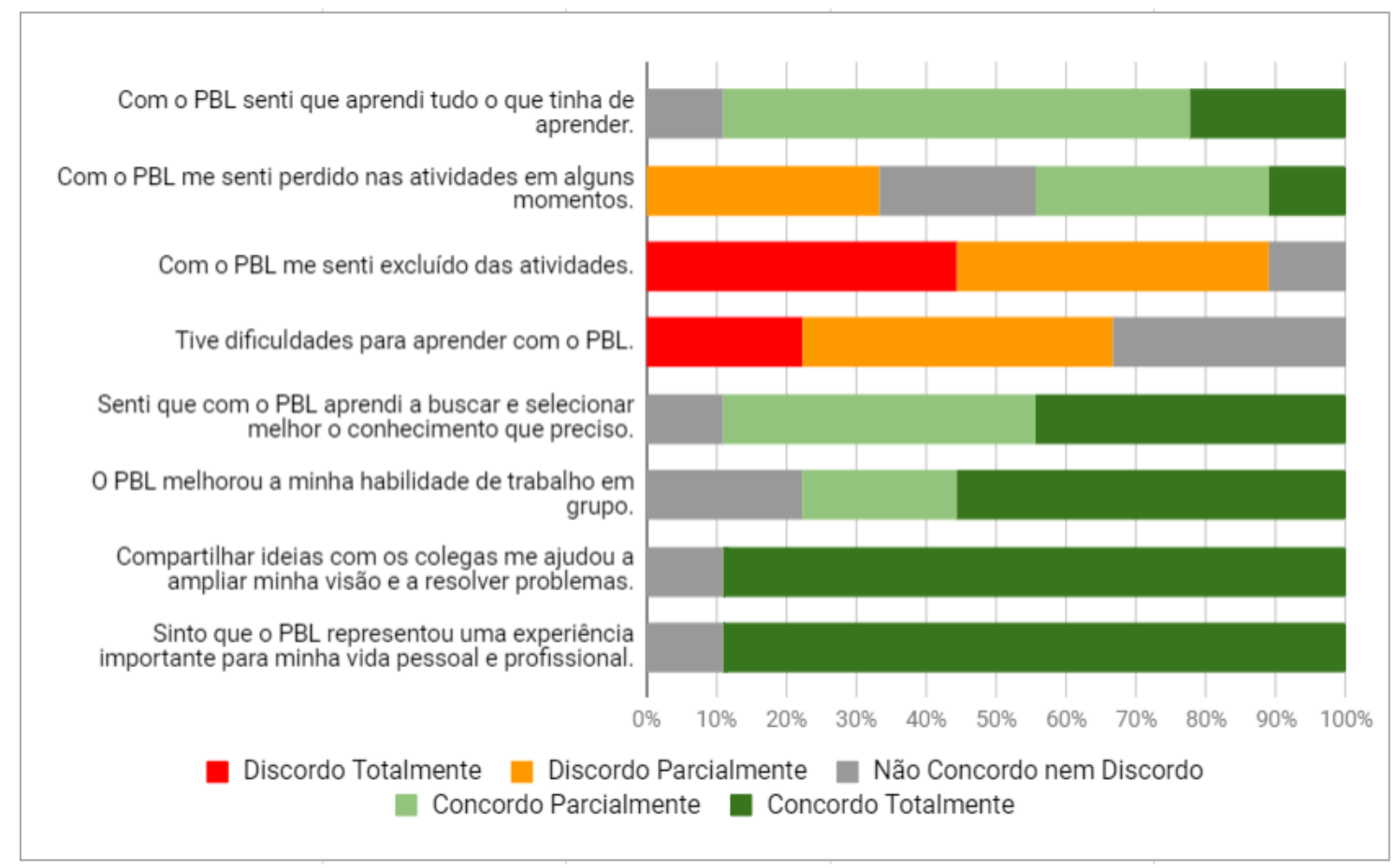

Figura 2. Percepções sobre PBL

Percepções sobre a metodologia tradicional. A Figura 3 aponta que, embora em menor percentual que nas metodologias ativas, os estudantes afirmaram buscar ferramentas para aprender algum assunto independente de solicitações da professora. 55,6\% concordaram total ou parcialmente que tomaram a iniciativa e $44,4 \%$ dos alunos se posi- 
VI Congresso Brasileiro de Informática na Educação (CBIE 2017)

Anais dos Workshops do VI Congresso Brasileiro de Informática na Educação (WCBIE 2017)

cionaram de forma neutra. A maior parte dos estudantes $(66,7 \%)$ se posicionou de forma neutra quanto a sentir que as aulas expositivas tinham um papel importante em sua aprendizagem. A respeito de se sentirem motivados durante as aulas expositivas, a maior parte dos estudantes $(55,5 \%)$ se mostrou neutra sobre esta afirmação. Sobre as aulas expositivas melhorarem sua aprendizagem, 22,2\% dos participantes discordaram parcialmente, $33,3 \%$ se mostraram neutros e 44,4\% concordaram parcialmente com esta afirmação.

Finalmente, quanto a gostar de aprender com aulas expositivas, a maioria dos participantes se posicionou de maneira neutra $(44,4 \%)$ ou discordou parcial ou totalmente da afirmação $(33,3 \%)$. Comparativamente, $66,7 \%$ dos alunos discordaram total ou parcialmente sobre aprenderem mais com aulas expositivas do que com metodologias ativas. Apenas $11,1 \%$ dos estudantes concordam parcialmente com esta afirmação. Estes últimos dois resultados mostram que há uma preferência pela abordagem ativa: tanto gostam mais desta metodologia quanto sentem que sua aprendizagem é melhor com ela.

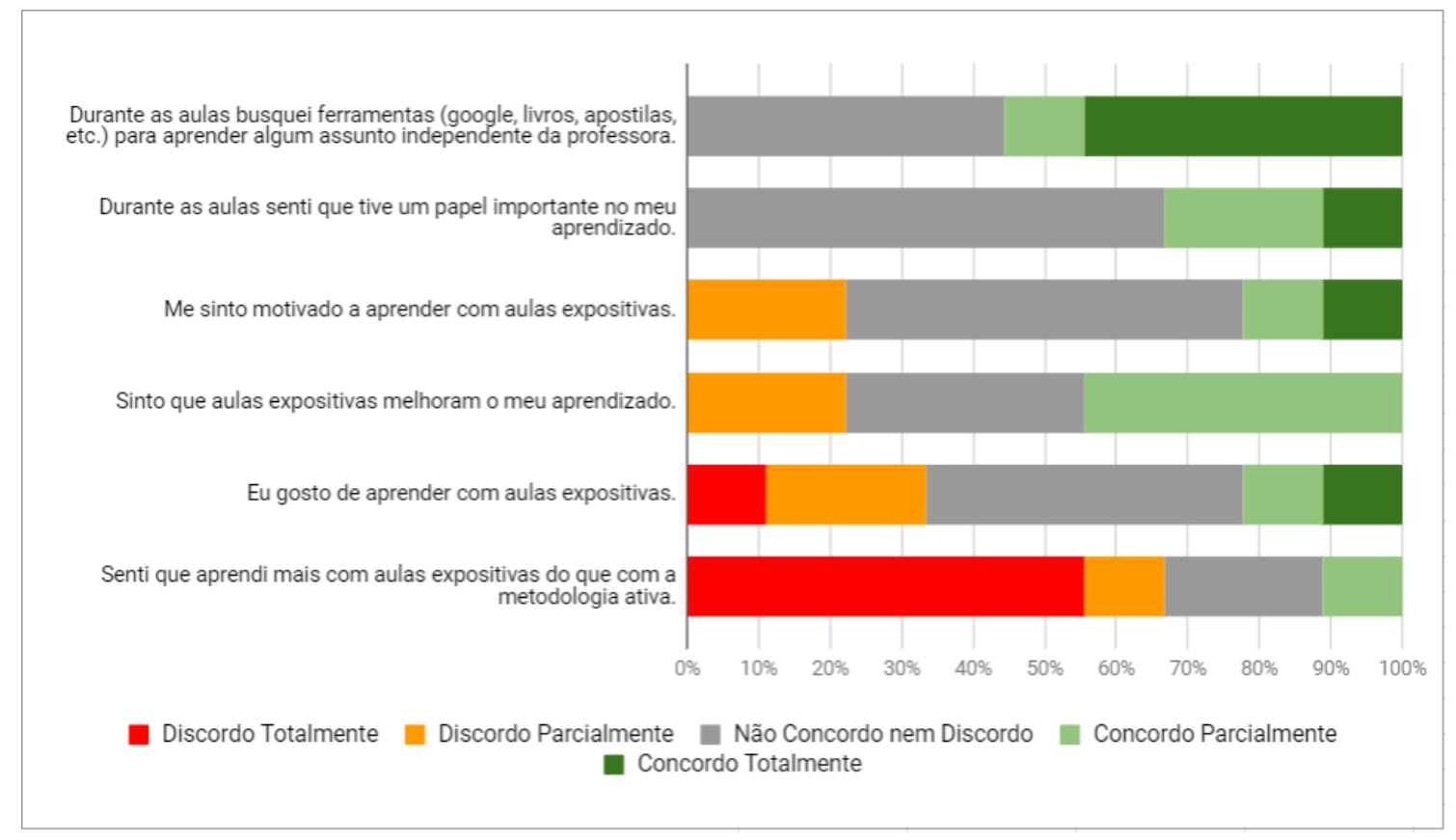

Figura 3. Percepções sobre a metodologia tradicional de aprendizagem

\section{Discussão}

Esta seção discute os resultados a partir de três aspectos: autonomia, motivação e pontos negativos de PBL.

Autonomia. As diferenças entre as percepções sobre as aulas tradicionais e as metodologias ativas já são evidenciadas pela sensação de autonomia dos estudantes. Durante a utilização de metodologias ativas, os estudantes relataram que buscaram mais materiais extra-classe. Isso foi fundamental para o sucesso da avaliação, já que eles se mostraram autônomos e empolgados com o desafio proposto. Mesmo sem o apoio de aulas tradicionais sobre armazenamento de dados em disco, eles discutiram em equipe e chegaram à conclusão de que utilizariam um banco de dados para este fim, resgatando o conteúdo de uma disciplina anterior. Isto foi além das expectativas da professora, que supunha que os estudantes utilizariam o conceito de arquivos, por ser uma solução mais simples. 
VI Congresso Brasileiro de Informática na Educação (CBIE 2017)

Anais dos Workshops do VI Congresso Brasileiro de Informática na Educação (WCBIE 2017)

Sobre PBL em particular, a maior parte dos estudantes acredita que alcançou o aprendizado que deveria. Isto se confirmou nas sessões tutoriais, já que eles se mostraram capazes de relacionar os requisitos com o conteúdo previamente apresentado em sala de aula, inclusive o de outras disciplinas. Os estudantes também se mostraram conscientes das limitações dos seus projetos, buscando a professora posteriormente para solucionar dúvidas a respeito da qualidade do código. Também foi relevante a melhora na habilidade de buscar e filtrar materiais de estudo, o que, mais uma vez, está relacionado com o aumento da autonomia.

Motivação. Outro ponto de destaque observado das metodologias de aprendizagem ativa em relação às tradicionais é o impacto na motivação dos estudantes. No decorrer das sessões tutoriais, foi perceptível a motivação deles. Eles levaram ideias para compartilhar com a turma, tornando as discussões ricas em conteúdo. Este aspecto é confirmado pelos resultados referentes ao sentimento de que metodologias ativas potencializaram a aprendizagem e à sensação de que o compartilhamento de ideias foi efetivo para a resolução de problemas. A dificuldade encontrada no desafio do armazenamento os motivou a buscar como implementar a solução utilizando uma linguagem diferente e estimulou grande parte da turma a trabalhar em conjunto no desenvolvimento do modelo do banco de dados. Este fato pode ser relacionado ao papel que o estudante sente desempenhar na sessão tutorial, que é percebido nas afirmações sobre a sensação de ter um papel importante no aprendizado e na motivação em aprender.

Pontos negativos. O uso de PBL, apesar de ter mostrado pontos positivos, também apresentou fraquezas. Houve relatos de estudantes que se sentiram perdidos ou excluídos nas atividades. Esta sensação pode ter ocorrido durante as discussões das diferentes ideias propostas, quando alguns estudantes ficavam mais quietos que outros. Durante uma ocasião em particular, um deles discordou fortemente dos demais, preferindo seguir com o trabalho individualmente. Embora não tenha abandonado as discussões, ele se absteve de comentar sobre o ponto que gerou o conflito. Apesar dos conflitos de opinião, a maioria dos estudantes concordou que as sessões PBL auxiliaram na habilidade de trabalho em grupo e que trabalhar em grupo potencializou a sua aprendizagem.

\section{Conclusões}

Esta pesquisa descreve a utilização de aprendizagem baseada em problemas (PBL) na disciplina de Desenvolvimento de Sistemas I em uma turma do curso técnico em Informática do SENAI Bahia, analisando as percepções dos estudantes sobre esta e outras metodologias de aprendizagem ativa. Após utilizar aulas tradicionais para introduzir conceitos, PBL foi aplicada numa tentativa de aumentar a autonomia e motivação dos estudantes no desenvolvimento de seus sistemas.

Os resultados deste trabalho mostram que, apesar de ser mais largamente utilizada na educação superior, PBL também se constitui como opção para cursos técnicos, principalmente se aliado a outras metodologias de aprendizagem ativa. No contexto médiotécnico, onde o conhecimento prático, trabalho em grupo e resolução de problemas são requisitos para o sucesso dos egressos na indústria, envolvê-los em atividades que sejam relacionadas com a vida real é fundamental.

Notamos uma percepção positiva quanto ao uso de metodologias ativas de aprendizagem, inclusive com o uso do PBL que, apesar de ter apresentado pontos fracos, mostrou 
VI Congresso Brasileiro de Informática na Educação (CBIE 2017)

Anais dos Workshops do VI Congresso Brasileiro de Informática na Educação (WCBIE 2017)

ser uma boa opção para os estudantes desenvolverem habilidades e se sentirem motivados. Apesar de as aulas tradicionais também apresentarem pontos positivos, as respostas e o comportamento em sala de aula dos estudantes demonstram uma preferência pelas metodologias ativas.

Após as sessões tutoriais realizadas na turma, um outro professor da instituição percebeu a motivação dos estudantes e passou a estudar a possibilidade de utilizar PBL em suas disciplinas, sendo esta um efeito inesperado desta pesquisa.

Espera-se que este trabalho possa contribuir na compreensão dos efeitos da utilização de metodologias de aprendizagem ativas com estudantes de nível médio. Como trabalhos futuros, pretendemos realizar uma pesquisa qualitativa para identificar mais detalhes da interação dos estudantes com a metodologia e, inclusive, replicar a experiência com alunos menos experientes e que tiveram menos contato com metodologias de aprendizagem ativa.

\section{Referências}

Albanese, M. A. and Mitchell, S. (1993). Problem-Based Learning: A Review of Literature on Its Outcomes and Implementation Issues. Academic medicine, 68(1):52-81.

Angelo, M. F., Bertoni, F. C., Santos, J. A. M., and Loula, A. (2010). Análise da Aplicação do Método PBL no Ensino de Programação em Engenharia de Computação. In PBL 2010 - International Conference on Problem-Based Leaning and Active Learning Methodologies.

Angelo, M. F., Loula, A. C., Bertoni, F. C., and Santos, J. A. M. (2014). Aplicação e Avaliação do Método PBL em um Componente Curricular Integrado de Programação de Computadores. Revista de Ensino de Engenharia, 33(2).

Barrows, H. and Tamblyn, R. (1980). Problem Based-Learning: An Approach to Medical Education, volume 1. Springer Publishing Company.

Berbel, N. A. N. (1998). A Problematização e a Aprendizagem Baseada em Problemas. Interface, 2(2):139-154.

Bittencourt, R. and Figueiredo, O. (2003). O Currículo do Curso de Engenharia de Computação da UEFS: Flexibilização e Integração Curricular. In XI Workshop sobre Educação em Computação - XXIII Congresso da Sociedade Brasileira de Computação, pages 171-182, Campinas, São Paulo. SBC.

Bittencourt, R. A., Rocha, A. S., Santana, B. L., Santana, C. S., Carneiro, D. A., Borges, G. A., Chalegre, H. S., Silva, J. F. J., Santos, J. M. J., Silva, L. A., and Andrade, P. H. M. O. (2013a). Aprendizagem de Programação Através de Ambientes Lúdicos em um Curso de Engenharia de Computação: Uma Primeira Incursão. In XXI Workshop sobre Educação em Computação - XXXIII Congresso da Sociedade Brasileira de Computação.

Bittencourt, R. A., Rodrigues, C. A., and Cruz, D. S. S. (2013b). Uma Experiência Integrada de Programação Orientada a Objetos, Estruturas de Dados e Projeto de Sistemas com PBL. In XXI Workshop sobre Educação em Computação - XXXIII Congresso da Sociedade Brasileira de Computação, Maceió. SBC. 
VI Congresso Brasileiro de Informática na Educação (CBIE 2017)

Anais dos Workshops do VI Congresso Brasileiro de Informática na Educação (WCBIE 2017)

Cravo, A. C. (2012). Análise das causas da evasão escolar do curso técnico de informática em uma faculdade de tecnologia de florianópolis. Revista Gestão Universitária na América Latina-GUAL, 5(2):238-250.

Creswell, J. W. (2010). Projeto de Pesquisa: Métodos Qualitativo, Quantitativo e Misto. Artmed.

Kölling, M. (1999a). The Problem of Teaching Object-Oriented Programming, Part 1: Languages. Journal of Object-oriented programming, 11(8):8-15.

Kölling, M. (1999b). The Problem of Teaching Object-Oriented Programming, Part 2: Environments. Journal of Object-Oriented Programming, 11(9):6-12.

Machado, M. R., Moreira, R., and Priscila, R. (2006). Educação Profissional no Brasil, Evasão Escolar e Transição para o Mundo do Trabalho. In I Colóquio Internacional sobre Educação Profissional e Evasão Escolar.

Oliveira, A. M. C. A., dos Santos, S. C., and Garcia, V. C. (2013). PBL in Teaching Computing: An Overview of the Last 15 Years. In FIE 2013 - Frontiers in Education Conference, pages 267-272. IEEE.

Prince, M. (2004). Does Active Learning Work? A Review of the Research. Journal of Engineering Education, 93(July):223-231.

Santos, C. S., Santos, A. H. M., Souza, S. M., Santos, D. M. B., and Bittencourt, R. A. (2015). Aprendendo Programação Orientada a Objetos com uma Abordagem Lúdica Baseada em Greenfoot e Robocode. In COBENGE 2015 - XLIII Congresso Brasileiro de Educação em Engenharia.

Santos, D. M. B., Pinto, G. R. P. R., Sena, C. P. P., Bertoni, F. C., and Bittencourt, R. A. (2007). Aplicação do Método de Aprendizagem Baseada em Problemas no Curso de Engenharia de Computação da Universidade Estadual de Feira de Santana. In COBENGE 2007 - XXXV Congresso Brasileiro de Educação em Engenharia, pages 2A07.1-2A07.14, Curitiba.

Santos, J. A. M. and Ângelo, M. F. (2009). Análise de Problemas Aplicados em um Estudo Integrado de Programaçao Utilizando PBL. In XVII Workshop sobre Educação em Computação - XXIX Congresso da Sociedade Brasileira de Computação, Bento Gonçalves, RS.

Santos, J. A. M., Angelo, M. F., and Loula, A. (2008a). Experiências em um Estudo Integrado de Programaçao usando PBL. In XVI Workshop sobre Educação em Computação - XXVIII Congresso da Sociedade Brasileira de Computação.

Santos, J. A. M., Ângelo, M. F., and Loula, A. (2008b). Utilização do Método PBL em um Estudo Integrado de Programação. In COBENGE 2008 - XXXVI Congresso Brasileiro de Educação em Engenharia.

Uden, L. and Beaumont, C. (2005). Technology and Problem-Based Learning. Information Science Publishing.

Vahldick, A. (2007). Uma Experiência Lúdica no Ensino de Programação Orientada a Objetos. In I Workshop de Ambientes de Apoio à Aprendizagem de Algoritmos e Programação - Simpósio Brasileiro de Informática na Educação. 